\title{
Isolation, Identification, and Antibiotics Susceptibility Determination of Proteus Species Obtained from Various Clinical Specimens in Erbil City
}

\author{
Treska Dh. Kamil ${ }^{1,2 *}$, Sanaria F. Jarjes ${ }^{2}$ \\ ${ }^{1}$ Department of Biology, College of Science, Cihan University - Erbil, Iraq, ${ }^{2}$ Department of Medical Laboratory Technology, Erbil Health \\ Technical College, Erbil Polytechnic University, Kurdistan Region - Iraq
}

\section{*Corresponding author: \\ Treska Dh. Kamil, \\ Department of Biology, \\ College of Science, Cihan \\ University - Erbil, Iraq. \\ E-mail: treska.dhia95@ \\ gmail.com}

Received: 29 August 2019

Accepted: 18 November 2019

Published: 01 December

2019

\section{DOI}

10.25156/ptj.v9n2y2019.pp86-92

\section{A B S T R A C T}

Fifty-two Proteus isolates, (47) Proteus mirabilis, (4) Proteus vulgaris, and (1) Proteus hauseri are being isolated from (200) clinical specimens taken from patients admitted to different hospitals in Erbil city/ Kurdistan region of Iraq. Specimens were of urine, wounds swabs, burn swabs, vaginal swabs, ear swabs, eye swabs, and sputum. All isolates were identified depending on cultural, morphological, biochemical characteristics, and confirmatory VITEK 2 system. Furthermore, VITEK 2 (antibiotic susceptibility testing) panel was used to determine the antibiotic susceptibility of Proteus isolates, and the results showed that all isolates were entirely resistant to tetracycline and tigecycline $(100 \%)$, but sensitive to meropenem. Furthermore, the present study reported a case of rare Proteus species - $P$. hauseri - isolated from a patient with urinary tract infection in Erbil City which characterized by no swarming on blood agar.

Keywords: Antibiotic resistance; Erbil city; Proteus hauseri; Proteus species; VITEK 2

\section{INTRODUCTION}

The genus Proteus is a Gram-negative rod-shaped bacterium belongs to the Enterobacteriaceae family, where it is placed in the tribe Proteeae, together with the genera Morganella and Providencia (Rosalski et al., 2012). Since this genus was first described in 1885 by German microbiologist Gustav Hauser, Proteus, and in particular Proteus vulgaris, has undergone a number of major taxonomic revisions (O'Hara et al., 2000a).

In1982, Hickman et al. separated P. vulgaris into three biogroups on the basis of indole production. Biogroup one was indole negative and represented a new species, Proteus penneri, while biogroups two and three remained together as P. vulgaris. The studies of O'Hara et al. (2000b) confirmed the existence of four genomospecies within P. vulgaris biogroup 3, which were called Protens genomospecies 3, 4, 5 , and 6 . These authors have proposed that genomospecies three be named Proteus hauseri.

Currently, the genus Proteus consists of five species: Proteus mirabilis, P. vulgaris, P. penneri, P. hauseri, and Proteus myxofaciens, as well as three unnamed Proteus genomospecies (O'Hara et al., 2000b). P. myxofaciens is the only Proteus species without any significance in the pathogenicity of humans (Janda et al., 2006).
The most defining microbiologic characteristic of Proteus species is their swarming phenomenon, a multicellular differentiation process of short rods to elongated swarmer cells. It allows the population of bacteria to migrate on a solid surface. Swarming appears macroscopically as concentric rings of growth emanating from a single colony or inoculum (Jacobsen et al., 2008).

Microorganisms belonging to genus Proteus are widely distributed in the natural environment. They can be found in polluted water, in soil, and manure, where they play an important role in decomposing organic matter of animal origin. Besides, the saprophytic mode of life in the natural environment and in the intestines of humans and animals, Proteus species, under favorable conditions, are able to cause a variety of opportunistic nosocomial infections (Feglo et al., 2010). This pathogen has a diverse mode of transmission and hence can cause infection in different anatomical sites of the body (Nita et al., 2014), including those of the urinary tract (causes complicated UTIs with a higher frequency compared to other uropathogens and formation of urinary stones), respiratory tract, ear, nose, skin, burns, and wounds, it may also cause gastroenteritis (Jacobsen et al., 2008).

The constant increase in the antibiotic resistance of clinical bacterial strains has become an important clinical problem 
(Adamus-Bialek et al., 2013). The evolution and spread of various mechanisms of antimicrobial resistance among common human pathogenic members of Enterobacteriaceae are of increasing concern and lead to narrowing of available therapeutic options (Boucher et al., 2009). However, the multidrug-resistant strains of Proteus species have also been reported worldwide (Singla et al., 2015). They have the ability to resist several different types of antibiotics and called multi antibiotic resistant (Dadheech et al., 2015).

Therefore, this study is concerned with isolation and identification (ID) of Proteus species from various clinical samples taken from patients admitted to main hospitals in the Erbil City/Kurdistan region of Iraq, as well as determination the susceptibility patterns of these isolates to different antibiotics.

\section{MATERIALS AND METHODS}

\section{Samples Collection}

Two hundred clinical specimens were collected aseptically from patients with symptomatic infections admitted to different hospitals in Erbil City (Erbil Teaching Hospital, West Erbil Emergency Hospital, CMC Hospital, and PAR Hospital) during the period from October 1, 2018, to April 1, 2019. Specimens were of urine samples (123), wounds swabs (25), burn swabs (18), vaginal swabs (6), ear swabs (8), eye swabs (15), and sputum (5). The specimens were directly inoculated in Tryptone Soya Broth and streaked onto MacConkey agar and blood agar plates and incubated aerobically at $37^{\circ} \mathrm{C}$ for $24 \mathrm{~h}$.

\section{Identification of the Isolates}

Isolates were identified depending on cultural, morphological, biochemical characteristics (Betty et al., 2007), and confirmatory VITEK 2 system using (ID) GN cards (bioM'erieux Inc. USA).

\section{Antibiotic Susceptibility Testing (AST)}

AST-N326 panels (bioM'erieux Inc. USA) were used to determine the antibiotic susceptibility.
The isolates were processed as per the manufacturer's instructions for ID and AST. The results were interpreted using VITEK 2 software version 08.01, and final results were obtained automatically.

\section{RESULTS}

\section{Isolation of Proteus Species}

Out of 200 clinical specimens of different infection sources, 52 isolates (26\%) were identified as Proteus spp. They were isolated from $35(28.45 \%)$ urine samples, $9(36 \%)$ wound swabs, $5(27.77 \%)$ burn swabs, $2(33.33 \%)$ vaginal swabs, and $1(20 \%)$ sputum cultures, while results showed complete absence of isolates from eye and ear swabs [Table 1].

The percentages of Proteus spp. isolated from various clinical specimens are presented in Figure 1. Of (52) Proteus isolates, Proteus mirabilis was the most common isolate accounting for 47 (90.4\%), followed by P. vulgaris $4(7.7 \%)$ and only one isolate $(1.9 \%)$ of $P$. hauseri, were isolated.

\section{Identification of Proteus Isolates}

The isolates were first identified as related to the genus Proteus by swarming phenomenon on blood agar, the cultures' characteristic smell, and the pale appearance of bacteria (non-lactose fermenting) on the MacConkey agar.

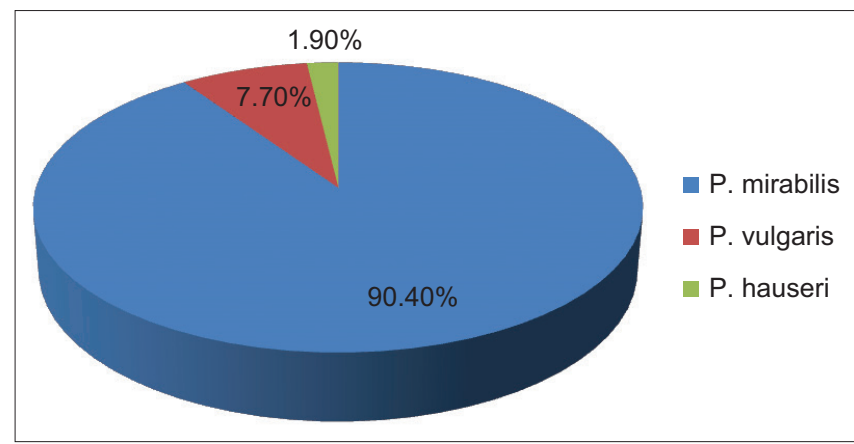

Figure 1: Percentage of Proteus species isolated from different specimens

Table 1: Isolation source and percentage of Proteus isolates

\begin{tabular}{|c|c|c|c|c|c|c|}
\hline \multirow[t]{2}{*}{ Isolation source } & \multirow[t]{2}{*}{ Number of samples } & \multicolumn{3}{|c|}{$\begin{array}{c}\text { Number of Proteus spp. Isolated } \\
\text { per source }\end{array}$} & \multirow[t]{2}{*}{$\begin{array}{l}\text { Total number of Proteus } \\
\text { isolates per source }\end{array}$} & \multirow[t]{2}{*}{$\begin{array}{l}\text { Percentage of Proteus } \\
\text { isolates per source }\end{array}$} \\
\hline & & P. mirabilis & P. vulgaris & P. hauseri & & \\
\hline Urine & 123 & 33 & 1 & 1 & 35 & 28.45 \\
\hline Wounds & 25 & 6 & 3 & 0 & 9 & 36.00 \\
\hline Burns & 18 & 5 & 0 & 0 & 5 & 27.77 \\
\hline Eye & 15 & 0 & 0 & 0 & 0 & 0.00 \\
\hline Ear & 8 & 0 & 0 & 0 & 0 & 0.00 \\
\hline Vagina & 6 & 2 & 0 & 0 & 2 & 33.33 \\
\hline Sputum & 5 & 1 & 0 & 0 & 1 & 20.00 \\
\hline Total & 200 & 47 & 4 & 1 & 52 & 26.00 \\
\hline
\end{tabular}

P. mirabilis: Proteus mirabilis, P. vulgaris: Proteus vulgaris, $P$. hauseri: Proteus hauseri 
Also by microscopic examination of the bacteria, which appeared as straight rods and Gram negative when it stained with Gram stain.

Several conventional biochemical tests were done to characterize the suspected Proteus isolates. The results indicated that these isolates were belonged to three Proteus species; P. mirabilis, P. vulgaris, and P. hauseri. All the (52) Proteus isolates showed positive results to the catalase, urease, and motility, but were negative to citrate and oxidase test. Forty-seven of the (52) Proteus isolates gave clearly negative results for indole and salicin fermentation tests and considered as P. mirabilis. On the other hand, P. vulgaris was represented by (4) isolates when such isolates gave positive results to indole and salicin fermentation tests. However, only one isolate gave a positive result for the indole test and negative for the salicin fermentation test and P. hauseri was suspected [Table 2].

\begin{tabular}{|c|c|c|c|}
\hline \multirow[t]{2}{*}{ Test } & \multicolumn{3}{|c|}{ Proteus isolates } \\
\hline & $\begin{array}{l}\text { P. mirabilis* } \\
(n=47)\end{array}$ & $\begin{array}{l}P \text {. vulgaris } \\
(n=4)\end{array}$ & $\begin{array}{l}\text { P. hauseri } \\
(n=1)\end{array}$ \\
\hline Oxidase & - & - & - \\
\hline Catalase & + & + & + \\
\hline Urease & + & + & + \\
\hline \multicolumn{4}{|l|}{ SIM test } \\
\hline H2S Production & + & + & + \\
\hline Indole & - & + & + \\
\hline Motility & + & + & + \\
\hline Salicin fermentation & - & + & - \\
\hline Citrate & - & - & - \\
\hline
\end{tabular}

${ }^{*} \mathrm{n}$ : Number of isolates, -: A negative result, $+:$ A positive result.

P. mirabilis: Proteus mirabilis, P. vulgaris: Proteus vulgaris,

P. hauseri: Proteus hauseri
For confirmation of the results, VITEK 2 system (ID) GN cards were used and the results are indicated in Table 3.

\section{Antibiotic Susceptibility Determination of Proteus Isolates}

The susceptibility patterns of the Proteus isolates are presented in Table 4. It was found that the more effective antibiotic against isolates was the Meropenem, where all Proteus isolates were sensitive to it. Adversely, the less effective antibiotics were tetracycline and tigecycline when they were resisted by all isolates. However, the effect of other antibiotics was variable among the Proteus isolates.

Antibiotic resistance profile [Figure 2] revealed that generally a vast of resistance was detected among the $P$. mirabilis isolates against the antibiotics used. It was found that out of (47) P. mirabilis isolates, $100 \%$ resistance property was found to piperacillin, aztreonam, tetracycline, and tigecycline; more than $90 \%$ resistance to piperacillin $\backslash$ tazobactam, ceftazidime, cefepime, imipenem, ciprofloxacin, and trimethoprim/sulfamethoxazole; and about $70 \%$ or less resistance pattern was identified to netilmicin, tobramycin, and levofloxacin.

This study also observed resistance of $P$. vulgaris isolates to tetracycline and tigecycline $(100 \%)$, aztreonam and netilmicin (75\%), cefepime and levofloxacin (50\%), cefotaxime, amikacin, and ciprofloxacin (25\%), while all $P$. vulgaris isolates were sensitive to other tested antibiotics.

On the other hand, P. hauseri isolate was found to be resistant to piperacillin, ceftazidime, aztreonam, imipenem, tetracycline, and tigecycline, as illustrated in Figure 2.

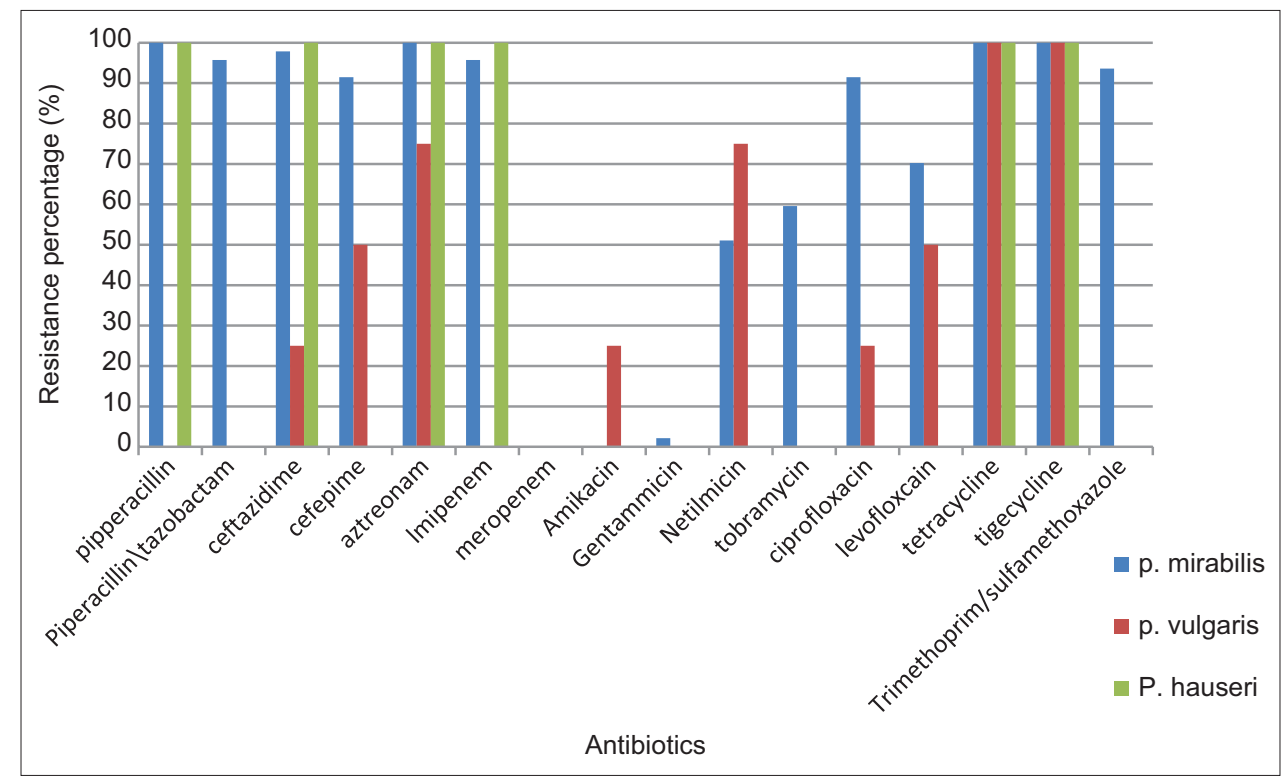

Figure 2: Antibiotic resistance profile of isolated Proteus species 
Table 3: The biochemical identification results of Proteus isolates obtained with (ID) GN cards of VITEK 2 system

\begin{tabular}{|c|c|c|c|c|}
\hline Well No. & Symbol/Test & P. mirabilis & P. vulgaris & P. hauseri \\
\hline 2 & Ala-Phe-Pro-ARYLAMIDASE & - & - & - \\
\hline 3 & ADONITOL & - & - & - \\
\hline 4 & L-PyrrolidonyI-ARILAMIDASE & - & - & - \\
\hline 5 & L-Arabitol & - & - & - \\
\hline 7 & D-CELLOBIOSE & - & - & - \\
\hline 9 & BETA-GALACTOSIDASE & - & - & - \\
\hline 10 & H2S PRODUCTION & + & + & + \\
\hline 11 & BETA-N-ACETYL-GLUCOSAMINIDASE & - & - & - \\
\hline 12 & GlutamyIArylamidase pNA & - & - & - \\
\hline 13 & D-Glucose & + & + & + \\
\hline 14 & GAMMA-GLUTAMYL-TRANSFERASE & + & - & + \\
\hline 15 & FERMENTATION-GLUCOSE & - & + & + \\
\hline 17 & BETA-GLUCOSIDASE & - & - & - \\
\hline 18 & D-MALTOSE & - & + & + \\
\hline 19 & D-MANNITOL & - & - & - \\
\hline 20 & D-MANNOSE & - & - & - \\
\hline 21 & BXYL (BETA-XYLOSIDASE) & - & - & - \\
\hline 22 & BETA-ALANINEARYLAMIDASE pNA & - & - & - \\
\hline 23 & L-Proline ARYLAMIDASE & - & - & + \\
\hline 26 & LIPASE & - & - & - \\
\hline 27 & PALATINOSE & - & - & + \\
\hline 29 & Tyrosine ARYLAMIDASE & - & - & + \\
\hline 31 & UREASE & + & + & + \\
\hline 32 & D-SORBITOL & - & - & - \\
\hline 33 & SACCHAROSE/SUCRALOSE & - & + & + \\
\hline 34 & d-TAGATOSE & - & - & - \\
\hline 35 & D-TREHALOSE & + & - & - \\
\hline 36 & CITRATE (SODIUM) & - & - & - \\
\hline 37 & MALONATE & - & - & - \\
\hline 39 & 5-KETO-D-GLUCONATE & - & - & - \\
\hline 40 & L-LACTATE alkalinization & - & - & + \\
\hline 41 & ALPHA-GLUCOSIDASE & - & - & + \\
\hline 42 & SUCCINATE alkalinization & - & - & + \\
\hline 43 & Beta-N-ACETYL-GALACTOSAMINIDASE & - & - & - \\
\hline 44 & ALPHA-galactosidase & - & - & - \\
\hline 45 & PHOSPHATASE & + & - & + \\
\hline 46 & Glycine Arylamidase & - & - & - \\
\hline 47 & ORNITHINE DECARBOXYLASE & + & - & - \\
\hline 48 & LYSINE DECARBOXYLASE & - & - & - \\
\hline 49 & DECARBOXYLASE bASE & - & - & - \\
\hline 53 & L-HISTIDINE assimilation & - & - & - \\
\hline 56 & COUMARATE & + & + & + \\
\hline 57 & BETA-GLUCORONIDASE & - & - & - \\
\hline 58 & O/129 RESISTANCE & + & - & + \\
\hline 59 & Glu-Gly-Arg-ARYLAMIDASE & - & - & - \\
\hline 61 & L-MALATE assimilation & - & - & + \\
\hline 62 & ELLMAN & - & - & + \\
\hline 64 & L-LACTATE assimilation & - & - & - \\
\hline
\end{tabular}

Other well numbers between 1 and 64 not designated in this table are empty. (-) a negative result, (+) a positive result. $P$. mirabilis: Proteus mirabilis, P. vulgaris: Proteus vulgaris, P. hauseri: Proteus hauseri

\section{DISCUSSION}

Two hundred clinical specimens were screened for Proteus spp. It was found that 52 isolates $(26 \%)$ were identified as Proteus spp. A near result was recorded by Al-
Bassam and Al-Kazaz (2013) who indicated that the total isolation percentage of Proteus spp. from different clinical specimens was $28.57 \%$, whereas the results were higher than those obtained by Feglo et al. (2010); Naz and Rasool (2013); A hmed (2015); and Latif et al. (2017) who mentioned 
Table 4: Antibiotic susceptibility patterns of Proteus isolates obtained with AST-N326 cards of VITEK 2 system

\begin{tabular}{|c|c|c|c|c|c|c|c|c|c|}
\hline \multirow[t]{3}{*}{ Antibiotics } & \multicolumn{9}{|c|}{ Number of Proteus isolates with susceptibility } \\
\hline & \multicolumn{3}{|c|}{ P. mirabilis $(n=47)$} & \multicolumn{3}{|c|}{ P. vulgaris $(n=4)$} & \multicolumn{3}{|c|}{ P. hauseri $(n=1)$} \\
\hline & S & $I$ & $\mathbf{R}$ & S & $I$ & $\mathbf{R}$ & S & $\mathbf{I}$ & $\mathbf{R}$ \\
\hline Piperacillin & 0 & 0 & 47 & 4 & 0 & 0 & 0 & 0 & 1 \\
\hline Piperacillin\tazobactam & 2 & 0 & 45 & 4 & 0 & 0 & 1 & 0 & 0 \\
\hline Ceftazidime & 0 & 1 & 46 & 3 & 0 & 1 & 0 & 0 & 1 \\
\hline Cefepime & 3 & 1 & 43 & 2 & 0 & 2 & 1 & 0 & 0 \\
\hline Aztreonam & 0 & 0 & 47 & 1 & 0 & 3 & 0 & 0 & 1 \\
\hline Imipenem & 2 & 0 & 45 & 4 & 0 & 0 & 0 & 0 & 1 \\
\hline Meropenem & 47 & 0 & 0 & 4 & 0 & 0 & 1 & 0 & 0 \\
\hline Amikacin & 44 & 0 & 3 & 3 & 0 & 1 & 1 & 0 & 0 \\
\hline Gentamicin & 11 & 35 & 1 & 4 & 0 & 0 & 1 & 0 & 0 \\
\hline Netilmicin & 23 & 0 & 24 & 1 & 0 & 3 & 1 & 0 & 0 \\
\hline Tobramycin & 19 & 0 & 28 & 4 & 0 & 0 & 1 & 0 & 0 \\
\hline Ciprofloxacin & 3 & 1 & 43 & 3 & 0 & 1 & 1 & 0 & 0 \\
\hline Levofloxcain & 13 & 1 & 33 & 2 & 0 & 2 & 1 & 0 & 0 \\
\hline Tetracycline & 0 & 0 & 47 & 0 & 0 & 4 & 0 & 0 & 1 \\
\hline Tigecycline & 0 & 0 & 47 & 0 & 0 & 4 & 0 & 0 & 1 \\
\hline Trimethoprim/sulfamethoxazole & 3 & 0 & 44 & 4 & 0 & 0 & 1 & 0 & 0 \\
\hline
\end{tabular}

${ }^{*} n$ : Number of isolates, S: Sensitive, I: Intermediate, R: Resistant. P. mirabilis: Proteus mirabilis, P. vulgaris: Proteus vulgaris, P. hauseri: Proteus hauseri

that Proteus spp. from clinical specimens represented (8.4\%), $(12.6 \%),(19 \%)$, and $(12.6 \%)$, respectively. The reason for the difference in isolation percentages may be due to the differences in the size of samples, isolation sources, and number of hospitals surveyed.

Of (52) Proteus isolates, 47 isolates (90.4\%) of different clinical specimens were identified as P. mirabilis. This result was agreed with Gonzalez and Bronze (2018) who reported that $P$. mirabilis causes $(90 \%)$ of Proteus infections and can be considered a community-acquired infection; Feglo et al. (2010) and Al-duliami et al. (2011), who mentioned that $P$. mirabilis is more widespread than $P$. vulgaris in clinical infections. Furthermore, Auwaerter (2008) declared that P. mirabilis is the species most commonly recovered from humans, especially from urinary and wound infections. It accounts for $90 \%$ of all infections caused by the Proteus species.

As per our knowledge, only two articles have been published regarding the isolation of $P$. hauseri. The first article was by O Hara et al. (2000b), in which only two cases of $P$. hauseri out of 52 isolates were isolated, and they have not mentioned whether swarming was present or not. In the second article, Ostwal et al. (2016) isolated the third case of $P$. hauseri from the stool; there was no swarming on blood agar so that these isolates may be misdiagnosed. Our $P$. hauseri isolate also did not show swarming.

Results showed that the highest percentage of Proteus isolates from clinical specimens was isolated from wound swabs specimens representing about 36\%. Being wound isolates were the highest percentage in the same trend with many results. This result agreed with similar studies conducted by Yah et al. (2001); Jones et al. (2003); Newman et al. (2006); Feglo et al. (2010); and Pandey and Tyagi (2013). In contrast with studies performed by Orett (1999); Reslinski et al. (2005); and Al-Bassam and Al-Kazaz (2013), which showed Proteus spp. to be more commonly in urine than in other clinical specimens.

In addition, high vaginal swabs from women with symptomatic vaginitis showed an isolation percentage of $33.33 \%$. However, the picture is not clear in the case of Proteus in women with vaginitis due to small numbers of infected women involved in this study.

Furthermore, results showed a complete absence of isolates from the eye and ear swabs. This may be due to the season of collecting samples and the possible medication taken before sampling.

The effect of different antibiotics on Proteus isolates was investigated. Interestingly, these isolates showed different susceptibility toward antibiotics used in this study [Table 4]. It has been found that the majority of the isolates were multidrug-resistant since they were resistant to three antibiotics or more. Proteus species can harbor numerous plasmid and integron-mediated determinants of antimicrobial resistance (Hall and Collis, 1998). In line with the findings of this study, resistance of Proteus species (P. mirabilis and P. vulgaris) against antibiotics has been reported by Newman et al., 2006; Mordi and Momoh, 2009; Feglo et al., 2010; Bahashwan and El Shafey, 2013; Kibret and Abera, 2014; and Ahmed, 2015. Although some antibiotics to which Proteus species are known to be 
sensitive, now they appear to be resistant or less effective. According to De Francesco et al. (2007), etiology and drug resistance change through time as well as may be due to random and improper use of these antibiotics. Our $P$. hauseri isolate was sensitive to meropenem, amikacin, ciprofloxacin, gentamicin, trimethoprim/sulfamethoxazole, and some other antibiotics, whereas the $P$. hauseri isolate of Ostwal et al. (2016) was only sensitive to meropenem. O'Hara's $P$. hauseri isolates were sensitive to amikacin, ciprofloxacin, gentamicin, as well as trimethoprim/ sulfamethoxazole and resistant to tetracycline, which are close to some extent with our findings.

\section{CONCLUSIONS}

In this study, P. mirabilis, P. vulgaris, and P. hauseri are the species implicated in Proteus infections in Erbil City. P. mirabilis was predominant species among patients with Proteus infections and wounds recorded the highest percentage of Proteus isolation. Furthermore, a case of rare Proteus species $-P$. hauseri - isolated from a patient with urinary tract infection and characterized by no swarming on blood agar.

Results are recommended prescribing of Meropenem in the treatment of Proteus species as it is the most effective antibiotic against these bacteria in vitro. Moreover, the results indicated that the resistance of Proteus species to some antibiotics is increased due to improper use of these antibiotics. Hence, knowledge of the local bacterial etiology and susceptibility patterns is required to trace any change that might have occurred.

\section{REFERENCES}

Adamus-Bialek, W., E. P. Parniewski. and W. Kaca. 2013. Comparison of antibiotic resistance patterns in collections of Escherichia coli and Proteus mirabilis uropathogenic strains. Mol. Biol. Rep. 40(4): 3429-3435.

Ahmed, D. A. 2015. Prevalence of Proteus spp. in some hospitals in Baghdad City. Iraqi J. Sci. 56(1): 665-672.

Al-Bassam, W. W. and A. K. Al-Kazaz. 2013. The isolation and characterization of Proteus mirabilis from different clinical samples. J. Biotechnol. Res. Center. 7(2): 24-30.

Al-Duliami, A. A., N. G. Nauman, A. S. Hasam and Z. H. Al-Azawi. 2011. Virulence factors of Proteus mirabilis isolated from patients otitis media in Baquba and its peripheries. Diyala J. Med. 1(1): 69-75.

Auwaerter, P. 2008. Antibiotic Guide. Johns Hopkins ABX (Antibiotic) Guide, Baltimore, MD.

Bahashwan, S. A. and H. M. El Shafey. 2013. Antimicrobial resistance patterns of Proteus isolates from clinical specimens. Eur. Sci. J. 9(27): 188-202.

Betty, A. F., D. F. Sahm and A. S. Weissfeld. 2007. Bailey and Scott's Diagnostic Microbiology. $12^{\text {th }}$ ed. Mosby, Inc., Elsevier Inc., Missouri.
Boucher, H. W., G. H. Talbot, J. S. Bradley, J. E. Edwards, D. Gilbert and L. B. Rice. 2009. Bad bugs, no drugs: No ESKAPE! An update from the Infectious Diseases Society of America. Clin. Infect. Dis. 48(1): 1-12.

Dadheech, T., R. Vyas and V. Rastogi. 2015. Antibiotics Resistance of aerobic bacterial isolates of Proteus mirabilis from sick layer chickens infected with septicemia and salinities in Ajmer region of Rajasthan. World J. Pharm. Pharm. Sci. 4(7): 2002-2011.

De Francesco, M. A., G. Ravizzola, L. Peroni, R. Negrini and N. Manca. 2007. Urinary tract infections in Brescia, Italy: Etiology of uropathogens and antimicrobial resistance of common uropathogens. Med. Sci. Monit. 13: BR136-BR144.

Feglo, P. K. S., Y. Gbedema, S. N. A. Quay, Y. Adu-Sarkodie and C. O. Okrah. 2010. Occurrence, species distribution and antibitics resistance of Proteus isolates: A case study at the Komfo Anokye teaching hospital in Ghana. Int. J. Pharm. Sci. Res. 1(9): 347-352.

Gonzalez, G. and M. S. Bronze. 2018. Proteus Infections: Background, Pathophysiology, Epidemiology. Available from: http://www.emedicine.medscape.com/article/226434-overview. [Last accessed on 2018 Sep 13].

Hall, R. M. and C. M. Collis. 1998. Antibiotic resistance in gramnegative bacteria: The role of gene cassettes and integrons. Drug Resist. Updat. 1: 109-119.

Hickman, F. W., A. G. Steigerwalt, J. J. $3^{\text {rd }}$ Farmer and D. J. Brenner. 1982. Identification of Proteus penneri sp. Nov., formerly known as Proteus vulgaris indole negative or Proteus vulgaris biogroup 1. J. Clin. Microbiol. 15: 1097-1102.

Jacobsen, S. M., D. J. Stickler, H. L. T. Mobley and M. E. Shirtliff. 2008. Complicated catheter-associated urinary tract infections due to Escherichia coli and Proteus mirabilis. Clin. Microbiol. Rev. 21(1): 26-59.

Janda, J. AbM. Bott, S.L. Khashe, S. Probert, W.,2006. Biochemical identification and characterization of DNA groups within Proteus vulgaris complex. J. Clin. Microbiol. 39(4): 1231-1234.

Jones, R., B. A. Vincent and W. B. Saunders. 2003. Bacteraemia, England, Wales and Northern Ireland. Commun. Dis. Rep. CDR Wkly. 15(34).

Kibret, M. and B. Abera. 2014. Prevalence and antibiogram of bacterial isolates from urinary tract infections at Dessie health research laboratory, Ethiopia. Asian Pac. J. Trop. Biomed. 4: 164-168.

Latif, B., S. Z. Aleabdyn and I. Ahmed. 2017. A Comparative bacteriological and molecular study on some virulence factor of Proteus spp isolated from clinical and environment specimens. Int. J. Curr. Res. Acad. Rev. 5(5): 26-33.

Mordi, R. M. and M. I. Momoh. 2009. Incidence of Proteus species in wound infections and their sensitivity pattern in the University of Benin Teaching Hospital. Afr. J. Biotechnol. 8(5): 725-730.

Naz, S. A. and S. A. Rasool. 2013. Isolation, production and characterization of bacteriocin produced by strains from indigenous environments. Pak. J. Bot., 45(1): 261-267.

Newman, M., E. A. Frimpong, A. Samoah-Adu and E. Sampane-Donkor. 2006. Resistance to Antimicrobial Drugs in Ghana. Ghanaian-Dutch Collaboration for Health Research and Development, Project No. 2001/GD/07, Technical Report Series No. 5. p1-19.

Nita, P., N. Sharma, R. Sharma, S. Hooja and R. K. Maheshwari. 2014. Prevalence of multidrug (MDR) and extensively drug resistant (XDR) Proteus species in a tertiary care hospital, India. J. Curr. Microbiol. Appl. Sci. 3(10): 243-252.

O'Hara, C., F. W. Brenner and J. M. Miller. 2000a. Classification, identification, and clinical significance of Proteus, Providencia, 
and Morganella. Clin. Microbiol. Rev. 13: 534-546.

O'Hara, C., F. W. Brenner, A. G. Steigerwalt, B. C. Hill, B. P. Holmes, A. D. Grimont, P. M. Hawkey, J. L. Penner, J. M. Miller and D. J. Brenner. 2000b. Classification of Proteus vulgaris biogroup 3 with recognition of Proteus hauseri sp. Nov., nom. rev. and unnamed Proteus genomo species 4, 5 and 6. Int. J. Syst. Evol. Microbiol. 50: 1869-1875.

Orett, F. A. 1999. Prevalence of Proteus species in urinary tract infections in a regional hospital in Trinidad. Zhonghua Yi Xue Za Zhi (Taipei). 62: 438-442.

Ostwal, K., P. Shah, L. Rebecca, N. Shaikh and K. Inole. 2016. A tale of two novel Proteus species Proteus hauseri and Proteus penneri. Int. J. Curr. Microbiol. Appl. Sci. 5(5): 84-89.

Pandey, J. K. and A. K. S. Tyagi. 2013. Prevalence of Proteus species in clinical samples, antibiotic sensitivity pattern and ESBL production. Int. J. Curr. Microbiol. Appl. Sci. 2(10): 253-261.
Reslinski, A., E. Gospodarek and A. Mikucka. 2005. Prevalence of multi-drug resistant Proteus species in clinical specimens and their susceptibility to antibiotics. Med. Dosw. Micribial. 57(2): 175-184.

Rosalski, A., A. Torzewska, M. Moryl, I. Kwil, A. Maszewska and A. Ostrowska. 2012. Proteus sp. an opportunistic bacterial pathogen-classification, swarming growth, clinical significance and virulence factors. Folia Biol. Oecol. 8(1): 1-17.

Singla, P., J. Sangwan, S. Garg, S. and U. Chaudhary. 2015. Prevalence and antibiogram of multidrug resistant uropathogenic isolates of Proteus mirabilis in a teaching tertiary care hospital. Int. J. Curr. Microbiol. Appl. Sci. 4(12): 675-682.

Yah, S. C., N. O. Egbanfona, S. Oranusi and A. M. Abouo. 2001. Widespread plasmid resistance genes among Proteus species in diabetic wounds of patients in Ahmadu Bello University Teaching Hospital (ABUTH) Zaria. Afr. J. Biotechnol. 6(15): 1757-1762. 